\author{
RESEARCH ARTICLE \\ 10.1029/2019JC015130 \\ Key Points: \\ - Assimilation of satellite sea surface \\ salinity (SSS) into ocean reanalyses \\ improves near-surface density \\ structure and mixed layer depth \\ - More realistic mixed layer depth \\ brought about by SSS assimilation \\ improves air/sea interaction and \\ acts to amplify oceanic Kelvin waves \\ - SSS assimilation initialization \\ extends useful ENSO forecasts from \\ 4 to 7 months and should be \\ included in operational forecast \\ systems
}

Correspondence to:

E. C. Hackert,

eric.c.hackert@nasa.gov

Citation:

Hackert, E. C., Kovach, R. M., Busalacchi, A. J., \& Ballabrera-Poy, J. (2019). Impact of Aquarius and SMAP satellite sea surface salinity observations on coupled El Niño/Southern Oscillation forecasts. Journal of Geophysical Research: Oceans, 124, 4546-4556. https://doi. org/10.1029/2019JC015130

Received 7 MAR 2019 Accepted 28 MAY 2019 Accepted article online 7 JUN 2019 Published online 4 JUL 2019

Corrected 27 AUG 2019

This article was corrected on 27 AUG 2019. See the end of the full text for details.

\section{Impact of Aquarius and SMAP Satellite Sea Surface Salinity Observations on Coupled El Niño/Southern Oscillation Forecasts}

\author{
Eric C. Hackert ${ }^{1}$ (D), Robin M. Kovach ${ }^{1,2}$ (D), Antonio J. Busalacchi ${ }^{3}$ (D) and \\ Joaquim Ballabrera-Poy ${ }^{4}$ (D)
}

${ }^{1}$ Global Modeling and Assimilation Office, NASA Goddard Space Flight Center, Greenbelt, MD, USA, ${ }^{2}$ Science Systems and Applications, Inc., Lanham, MD, USA, ${ }^{3}$ University Corporation for Atmospheric Research, Boulder, CO, USA,

${ }^{4}$ Institut de Ciències del Mar, CSIC, Barcelona, Spain
Abstract This study demonstrates the positive impact of including gridded Aquarius and Soil Moisture, Active/Passive (SMAP) sea surface salinity (SSS) into initialization of intermediate complexity coupled model forecasts for the tropical Indo-Pacific. An experiment that assimilates conventional ocean observations serves as the control. In a separate experiment, Aquarius and SMAP satellite SSS are additionally assimilated into the coupled model initialization. Analysis of the initialization differences with the control indicates that SSS assimilation causes a freshening and shallowing of the mixed layer depth near the equator and enhanced Kelvin wave amplitude. For each month from September 2011 to September 2017, 12-month-coupled ENSO forecasts are initialized from both the control and satellite SSS assimilation experiments. The experiment assimilating Aquarius and SMAP SSS significantly outperforms the control relative to observed NINO3.4 sea surface temperature anomalies. This work highlights the potential importance of inclusion of satellite SSS for improving the initialization of operational ENSO coupled forecasts.

Plain Language Summary El Niño/Southern Oscillation (ENSO) has far reaching climatic impacts over the globe so extending useful ENSO forecasts would be of great benefit for society. In response, NASA has developed satellite technology to observe the global hydrological cycle by measuring ocean sea surface salinity (SSS) from space. SSS, combined with temperature, helps to identify density changes and associated mixing near the ocean surface. Here we show results of two intermediate complexity coupled experiments designed to highlight the positive impact of SSS on ENSO forecasts. In the control, we assimilate all conventional satellite and in situ oceanographic information including satellite altimetry (matching current operational data assimilation schemes) but exclude SSS. In the second experiment, we add satellite SSS to our assimilation suite. Air/sea coupled model retrospective forecasts are then initialized from these two experiments and they show that satellite SSS assimilation improves coupled forecasts. For all lead times, the experiment with SSS assimilation has better correlation and root-mean-square difference with the ENSO metric (i.e., NINO 3.4 observed sea surface temperature anomalies). Density changes associated with SSS assimilation shoal the mixed layer near the equator and enhance the impact of large-scale ocean wave and wind changes that are associated with ENSO.

\section{Introduction}

El Niño/Southern Oscillation (ENSO) events have a significant impact on global weather and climate variability and so have been the primary focus for improving coupled forecasts. Assimilation of satellite sea level (SL) from altimetry (Ji et al., 2000) and subsurface temperature $\left(\mathrm{T}_{\mathrm{z}}\right)$ mostly from Argo have been found to improve the initialization of the thermocline for El Niño (Yang et al., 2010), and subsurface salinity $\left(\mathrm{S}_{\mathrm{z}}\right)$ has led to increased density and enhanced mixing and cooling of the upper ocean allowing the nascent La Niña of 2007 to remain relatively cool (Zhu et al., 2014). Assimilation of satellite sea surface temperature (SST) aids in specifying surface heat-flux forcing (Zhou et al., 2009), leading to improved short-term forecasts of the coupled system (Balmaseda \& Anderson, 2009). However, much less emphasis has been given to examining the impact of the near-surface ocean density structure and mixed layer processes on air-sea coupled prediction. Aquarius, whose overlaying scientific goal was to "quantify and understand the
Published 2019. This article is a U.S. Government work and is in the public domain in the USA. 
linkages among ocean circulation" (Lagerloef et al., 2008), was launched in June 2011 to accurately measure sea surface salinity (SSS) from space. Following upon Aquarius, the Soil Moisture, Active/Passive (SMAP) satellite (Fore et al., 2016) has been retasked to measure global fields of SSS starting in April 2015. The continuous stream of satellite SSS from 2011 to present allows a rigorous evaluation of the impact of satellite SSS and corresponding mixed layer density changes on ENSO predictions.

Recently, a few studies have addressed the impact of satellite SSS on ocean reanalyses. For example, Tranchant et al. (2018) and Martin et al. (2018) showed that assimilation of SSS from the Soil Moisture/ Ocean Salinity (SMOS) satellite (using similar L-band radiometer technology as Aquarius and SMAP) can add additional constraints to the coupled system to somewhat overcome deficiencies of model evaporation and precipitation. In particular, ocean model SSS assimilation has reduced the observational bias of salinity over much of the tropical Pacific including the Intertropical Convergence Zone (ITCZ), South Pacific Convergence Zone (SPCZ), and the western equatorial Pacific with the improvement extending down 30-50 m into the water column. During a simulation of the 2015 El Niño, Tranchant et al. (2018) found that patterns associated with SMOS SSS assimilation acted to enhance the propagation of tropical instability waves in the eastern Pacific and increase the acceleration of the warm/fresh pool migration to the east for the 2015 El Niño. On the other hand, Martin et al. (2018) found that the meridional SSS gradient is reduced near $5{ }^{\circ} \mathrm{N}$ by SMOS assimilation leading to SL changes and a reduction in tropical instability wave activity and a more zonal North Equatorial Counter Current. Near the equator, SMOS SSS assimilation leads to shallower MLD across the entire Pacific and, the anomalous eastward currents of the $2015 \mathrm{El}$ Niño are enhanced east of $150^{\circ} \mathrm{E}$. In a recent paper, Chakraborty et al. (2015) also found shallower values and an overall improvement in MLD for the tropical Pacific when assimilating Aquarius SSS data. In addition to SMOS, Martin et al. (2018) performed experiments using multiple SSS satellites (i.e., SMOS and Aquarius and SMOS and SMAP) that further improved the ocean analyses. Thus, the results of Tranchant et al. (2018), Martin et al. (2018), and Chakraborty et al. (2015) have clear implications for ENSO prediction and these improvements help to justify the implementation of SSS assimilation into operational forecast systems.

Beyond ocean reanalyses, the first study to examine the SSS impact on ENSO predictions was Ballabrera-Poy et al. (2002). Utilizing multiple regression analysis of SL, SST, and SSS, they found that SSS has significant impact on multivariate ENSO predictions from 6- to 12-month lead times. In particular, they found that off-equatorial SSS anomalies in the south-central Pacific at 6 months and western equatorial Pacific and SPCZ SSS anomalies at 9-12 months were especially effective at predicting ENSO (see, e.g., BallabreraPoy et al., 2002; Figures 2-6 for details).

Prior to the availability of Aquarius satellite SSS, Hackert et al. (2011) showed that assimilation of gridded in situ SSS into an ocean-atmosphere coupled model improves the resulting forecasts for the tropical Pacific Ocean. For 6-12 months, ENSO forecasts initialized from December to March, correlation with observed NINO3 SST anomalies increased by $0.2-0.5$, and the RMSD is reduced by $0.3-0.6{ }^{\circ} \mathrm{C}$ negating the wellknown Spring Predictability Barrier ENSO forecast problem. These forecast improvements were brought about by better representation of salinity anomalies in the western Pacific equatorial warm/fresh pool. The mechanisms for ENSO prediction improvements were as follows: Fresh anomalies advect from the Southern Hemisphere to the western equatorial region through subduction processes leading to increased barrier layer thickness and shoaled MLD. Fresh anomalies at the surface reduce mixing, decrease buoyancy, and shoal the thermocline leading to more efficient air/sea ENSO coupling.

Following this study, the positive impact of Aquarius SSS assimilation on ENSO forecasts was then demonstrated using an Indo-Pacific Hybrid Coupled Model (Hackert et al., 2014) that used a statistical atmosphere. The added benefit of assimilating Aquarius gridded SSS was tested by comparing 12-month-coupled predictions initialized using satellite SSS versus assimilation of gridded near-surface in situ salinity observations. When validated against observed NINO3 SST anomalies for September 2011 to February 2014, coupled predictions initialized from assimilation of any SSS improve upon the control (i.e., assimilation of $\mathrm{T}_{\mathrm{z}}$ ) and satellite SSS outperforms in situ, gridded, near-surface salinity assimilation. Experiments initialized with Aquarius SSS had higher correlation and lower RMSD from 5 to 11 months. Further analysis of the initialization experiments shows that Aquarius SSS assimilation reduces the MLD, again leading to more efficient air/sea coupling near the equator. In addition, the localized effects of assimilation of relatively less fresh satellite SSS near the equator and the dateline, and the associated increased relative density, result in 
enhanced mixing. This equatorial upwelling signal then propagates eastward to the NINO3 region, reducing the pervasive warm SST anomaly-biased forecasts. In addition, both the spatial coverage afforded by Aquarius and the observation quality contribute to satellite improvements relative to in situ SSS assimilation. Although only La Niña conditions were observed during the limited 30 months of satellite SSS data that were available at the time of publication, these results illustrated the potential improvement in coupled forecasts due to the assimilation of Aquarius satellite SSS for the tropical Indo-Pacific region. These limited results also point out the need to extend this study to improve the reliability of the results and to encompass more ENSO phases.

This current study expands upon the previous works on ENSO prediction by extending the satellite SSS to include both Aquarius and SMAP data and now covers both La Niña and El Niño forecast scenarios. In addition, this study now uses an intermediate-complexity coupled model with a more realistic atmosphere (detailed in section 3). The current study also assesses the potential benefit of assimilating satellite SSS within the context of more realistic operational coupled model forecasts. Using the Observing System Experiment approach of Global Ocean Data Assimilation Experiment OceanView (Oke et al., 2015), the control simulation assimilates all available conventional ocean information including satellite SL, SST, and in situ subsurface temperature $\left(\mathrm{T}_{\mathrm{z}}\right)$ and salinity $\left(\mathrm{S}_{\mathrm{z}}\right)$. A separate experiment additionally assimilates gridded fields of Aquarius V5 (Lilly \& Lagerloef, 2008) and SMAP V4.0 (Fore et al., 2016) SSS. The general methodology of this paper is to difference experiments with SSS assimilation versus the control without SSS assimilation to clearly identify the impact of SSS assimilation. Twelve-month forecasts are then generated for each month from September 2011 to September 2017 from the control and SSS assimilation experiments and are then validated using the observed NINO3.4 (i.e., $5^{\circ} \mathrm{S}-5^{\circ} \mathrm{N}, 170-120^{\circ} \mathrm{W}$ ) SST anomaly index (Reynolds et al., 2002).

The structure of the paper is described as follows: Section 2 explains the observations and data processing and briefly reviews satellite SSS comparisons with near-surface salinity. Section 3 describes the models and data assimilation methodology. Section 4 presents the results, and section 5 summarizes the results and provides conclusions.

\section{Observations and Data Processing}

Weekly gridded $1^{\circ} \times 1^{\circ}$ multisatellite AVISO sea level data (AVISO, 2013) and SST data (Reynolds et al., 2002) are assimilated into the ocean model. The source data for $T_{z}$ and $S_{z}$ data is comprised of the GTSPP (NODC, 2006), TAO/RAMA, and World Ocean Database (WOD13; Boyer et al., 2013) observation data. Satellite SSS data come from the latest release of the weekly Aquarius V5 gridded SSS product (Lilly \& Lagerloef, 2008) for the period August 2011 to June 2015 (currently, ftp://podaac-ftp.jpl.nasa.gov/ SalinityDensity/aquarius/L3/mapped/V5/7day/SCI, ). These gridded Aquarius data are combined with the 8-day running mean SMAP V4 data set (Fore et al., 2016) from April 2015 to present (i.e., currently, ftp://podaac-ftp.jpl.nasa.gov/allData/smap/L3/JPL/V4/8day_running/).

Gridding the data for Aquarius and SMAP are performed in a similar manner. The Aquarius/SMAP data processing system provides a bilinear interpolation of the along-track data using the search radius defined in (Lilly \& Lagerloef, 2008). Ascending and descending data are combined to formulate $0.25^{\circ}$ resolution grids which are then interpolated to $1^{\circ}$ grids for assimilation. This gridding technique is more comprehensively described in https://podaac.jpl.nasa.gov/dataset/AQUARIUS_L3_SSS_SMI_7DAY_V5 and the Aquarius and SMAP retrieval algorithms are described in Meissner et al. (2018).

A full analysis of the gridded SSS error with respect to near-surface Argo data is beyond the scope of this paper. However, Kao et al. (2018) show statistics for Aquarius V5 data versus near-surface Argo salinity. Their Figure 3 shows that the mean bias generally varies between -0.2 and 0.2 psu with positive (negative) bias in the Northern (Southern) Hemisphere within $10^{\circ}$ of the equator in the Pacific. For RMS, the values are generally less than $0.15 \mathrm{psu}$ in the tropics with a maximum of $0.2 \mathrm{psu}$ at the equator, a minimum at $20^{\circ} \mathrm{N}$ and $20{ }^{\circ} \mathrm{S}$ and rising values toward the poles. For more details about the Aquarius/Argo differences see Kao et al. (2018).

The SMAP salinity has also been validated against gridded Argo near-surface salinity products (ftp://podaac. jpl.nasa.gov/SalinityDensity/smap/docs/JPL-CAP-V42/SMAP_JPL_V4.2_Documentation.pdf). Figure 4.1 
of this document compares SMAP V4.2 versus the gridded products of Roemmich and Gilson (2009) and the Asia-Pacific Data Research Center (APDRC—apdrc.soest.hawaii.edu/datadoc/argo_iprc_gridded.php). The biases between SMAP SSS and these products are generally similar to the Aquarius comparisons. Namely, there are salty biases in the Northern Hemisphere of the Pacific and fresh in the south. However, unlike Aquarius, the amplitude of the biases is larger (i.e., -0.5 to $0.5 \mathrm{psu}$ ) and SMAP biases have a more prominent salty bias in the cold tongue of the tropical Pacific. For the RMS, the amplitude and pattern are generally similar to Aquarius. The RMS is largest at the equator (exceeding $0.4 \mathrm{psu}$ ) in the cold tongue and in the western Pacific, decreasing to about 0.15 psu at $20^{\circ} \mathrm{N}$ and $20^{\circ} \mathrm{S}$ and increasing poleward from there.

\section{Models and Data Assimilation Description}

Our Intermediate-Complexity Coupled Model (ICCM) allows computationally efficient modelling of the global wind and precipitation associated with the coupled ENSO system while at the same time resolving the main features of the oceanic ENSO. The ICCM couples a regional reduced-gravity, primitive-equation, sigma-coordinate ocean model (Gent \& Cane, 1989) with the SPEEDY (Simplified Parameterizations, primitivE-Equation DYnamics) global dynamical atmospheric model (Molteni, 2003). The ocean model component encompasses the tropical Indo-Pacific basin $\left(30^{\circ} \mathrm{N}-30^{\circ} \mathrm{S}, 34^{\circ} \mathrm{E}-76^{\circ} \mathrm{W}\right)$ and has a homogeneous zonal grid resolution of $1^{\circ}$ and a variable meridional grid (down to $1 / 3^{\circ}$ within $10^{\circ}$ of the equator). This resolution is dense enough to accurately simulate the large-scale ocean waves associated with ENSO (i.e., ocean Kelvin and Rossby waves). Open boundaries are treated as a sponge layer within $5^{\circ}$ of the north and south borders smoothly relaxing to World Ocean Atlas 2013 (WOA13; Locarnini et al., 2013; Zweng et al., 2013) values. The ocean model is comprised of a surface variable-depth mixed layer and 19 sigma layers below. The deep ocean (i.e., the level of no motion) is prescribed with $\mathrm{T}_{\text {bottom }}=6{ }^{\circ} \mathrm{C}$ and $\mathrm{S}_{\text {bottom }}=$ $35 \mathrm{psu}$. Starting from the WOA13 data as initial conditions, the model is spun up for 30 years until it reaches equilibrium and it is forced by the Modern-Era Retrospective Analysis for Research and Applications, Version 2 (MERRA-2; Gelaro et al., 2017) climatology of zonal and meridional winds, precipitation, cloudiness, and solar radiation. Reanalysis (i.e., ocean data assimilation) experiments are initialized from this climatological spin-up and the sensible and latent heat fluxes are computed from interannual MERRA-2 10-m wind using the same technique as Hackert et al. (2014). MERRA-2 precipitation forces fresh water flux and the riverine component has been estimated using the river flow data of (Dai \& Trenberth, 2002). Note that in this model, salinity does not relax back to climatological values but varies freely as a natural boundary condition (Huang, 1993). Full details about this ocean model configuration can be found in Hackert et al. (2017).

As a control for all reanalysis experiments, we assimilate gridded satellite SL, SST, and pointwise in situ $\mathrm{T}_{\mathrm{z}}$, $\mathrm{S}_{\mathrm{z}}$ anomalies (designated as CONTROL) into the ocean model using an Ensemble Reduced Order Kalman Filter (EROKF). The Kalman Filter equations for the EROKF are projected upon the basis derived from the Multivariate Empirical Orthogonal Functions (MEOFs) formed by three-dimensional temperature, salinity, zonal, meridional ocean velocities, layer thickness, and sea level from a long integration, 1984-2004, of the free model run. The EROKF is limited to 30 MEOFs since this number provides a reasonable accuracy and computational cost while at the same time avoiding overfitting. We utilize an ensemble technique to account for missing MEOF subspace which underestimates the analysis error covariance (see, i.e., Cane et al., 1996). At each 5-day assimilation cycle, all available observations within the month are projected onto the three-dimensional modes to obtain both the amount of signal accounted for by the assimilation subspace and the residual. The variance of the residuals accounts for both the signal incompatible with the model variability and the error due to the basis truncation. These variances are used to construct a diagonal matrix of model errors. Since the assimilation is limited to the tropical Indo-Pacific region, a single value is chosen for the observational error corresponding to $3 \mathrm{~cm}$ (Busalacchi et al., 1994), $0.3^{\circ} \mathrm{C}$ (Chakraborty et al., 2015), and 0.2 psu (Lagerloef et al., 2008) for SL, SST, and SSS, respectively. For $\mathrm{T}_{\mathrm{z}}$ and $\mathrm{S}_{\mathrm{z}}$, the observational error is chosen as $0.75{ }^{\circ} \mathrm{C}$ and $0.31 \mathrm{psu}$, respectively. Additional details about this technique and bibliographical references can be found in Hackert et al. (2014) and Ballabrera-Poy et al. (2001), respectively.

Version 4.1 of the SPEEDY model (Kucharski et al., 2006; Molteni, 2003) has roughly $3.75^{\circ}$ resolution, outputs data at the surface and eight standard sigma layers (925-30 mb) and has been demonstrated to be a quality dynamical atmospheric model (Kucharski et al., 2013). The cumulus momentum transport of 
Kim et al. (2008) has been added to the convective parameterization scheme to improve the tropical winds. The SPEEDY model parameterizes momentum, heat, moisture fluxes, radiation, and condensation. Convection is initiated by conditional instability. For a full description of this version of SPEEDY, see Kucharski et al. (2013).

The ICCM uses the anomaly coupling technique to combine the ocean and atmospheric models. For a complete description of the ICCM, see Hackert (2016) and Hackert et al. (2017). Using this technique, 12-month duration forecasts are completed starting from the 1st of the month from September 2011 to September 2017. While faster to run than operational coupled models (which use higher resolution atmospheric and ocean models and more complicated physical parameterizations), the use of this dynamical coupled ocean/atmosphere model is justified since the atmospheric time scale is much shorter than the ocean's. In addition, this ICCM validates favorably against more well-known operational coupled models (see, e.g., comparison to NOAA's CFSv2 in Hackert, 2016).

For the ocean reanalysis results, we will follow the common Observing System Experiment approach of Global Ocean Data Assimilation Experiment OceanView community (Oke et al., 2015). The experiments are summarized in Table 1. Both the CONTROL and SSS_ASSIM experiments assimilate all available in situ (i.e., $\mathrm{T}_{\mathrm{z}}$ and $\mathrm{S}_{\mathrm{z}}$ ) and satellite SL and SST data. The CONTROL experiment is spun-up from January 1993 to August 2011 and continued for the analysis period from September 2011 until September 2017. Additionally, all available gridded Aquarius and SMAP satellite SSS data are assimilated into the SSS_ASSIM experiment. Since no Aquarius or SMAP satellite SSS data exist prior to 2011, this experiment is spun-up over 1993 to August 2011 using assimilation of an optimal interpolation of near-surface $\mathrm{S}_{\mathrm{z}}$ (abbreviated as $\mathrm{SSS}_{\mathrm{OI}}$ in Table 1) and this method is detailed in (Hackert et al., 2014).

The periods for both the control and SSS assimilation experiments range from September 2011 to September 2017 and the validation observations extend to September 2018, giving 84 months to assess statistics for the reanalyses and forecasts. Aquarius V5 SSS is available from September 2011 until June 2015, and SMAP V4 data starts in March 2015 continuing until present. During the brief period of overlap, both Aquarius and SMAP data are assimilated.

\section{Results}

As a first step, we utilize the root-mean-square differences (RMSDs) between the model reanalyses and an optimal interpolation (OI) of all available in situ observations in order to validate the reanalysis results. The optimal interpolation is calculated for both salinity and temperature for all the standard WOA13 levels using the technique of (Hackert et al., 2014). Note that the first layer of salinity is the same as that which is used to spin up the satellite salinity experiment referenced as $\mathrm{SSS}_{\mathrm{OI}}$ in the previous section. A skill score is calculated using the following equation: Skill Score $=1-\left(\mathrm{RMSD}_{\mathrm{SSS} \_\mathrm{ASSIM}} / \mathrm{RMSD}\right.$

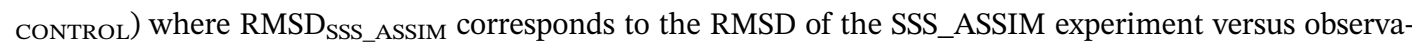
tions and $\mathrm{RMSD}_{\mathrm{CONTROL}}$ is the validation of the CONTROL experiment versus observations. The skill score is devised such that positive values indicate an improvement with respect to observations when satellite SSS is assimilated (i.e., SSS_ASSIM has lower RMSD with respect to observations than the CONTROL).

Figure 1a shows the results of these skill score tests for SSS. Assimilation of satellite SSS improves the nearsurface salinity validation especially in the western Pacific and in the Southern Hemisphere. Exceptions occur in the ITCZ, eastern edge of the SPCZ, and the eastern South Pacific. The first two of these may be explained due to differences in rainy regions between satellite SSS observations (that measure the top $\sim 1$ $\mathrm{cm}$ of the ocean) and in situ observations (that typically measure 5-m down into the water column). The differences for near-surface density are shown in Figure 1b. This plot generally confirms the SSS results, namely, that SSS_ASSIM outperforms the CONTROL in the western Pacific, Southern Hemisphere, and north of $10^{\circ} \mathrm{N}$.

MLD is defined by the density criteria (i.e., depth that the vertical density change, $\Delta \rho$ equals the surface $\rho$ value plus the equivalent $\Delta \rho$ assuming $\Delta \mathrm{T}=0.2{ }^{\circ} \mathrm{C}$ keeping salinity at depth equal to SSS; Sprintall \& Tomczak, 1992). Figure 1c shows clear improvement within the zonal band between $15{ }^{\circ} \mathrm{S}$ and $5{ }^{\circ} \mathrm{N}$. Positive values in this region indicate that the SSS_ASSIM experiment more closely matches the observed 
Table 1

Summary of the Coupled Model Experiments Used in this Paper

\begin{tabular}{lcc}
\hline Experiment Name & Period & Assimilation Data \\
\hline CONTROL & Jan 1993-Sep 2018 & SL, SST, $\mathrm{T}_{\mathrm{z}}, \mathrm{S}_{\mathrm{z}}$ \\
SSS_ASSIM & Sep 2011-Sep 2018 & SL, SST, $\mathrm{T}_{\mathrm{z}}, \mathrm{S}_{\mathrm{z}}$, and 10-day gridded fields of Aquarius V5 \\
& and SMAP V4.1 SSS & SL, SST, $\mathrm{T}_{\mathrm{z}}, \mathrm{S}_{\mathrm{Z}}$, and OI of near surface salinity (SSS \\
SSS & Jan 1993-Sep 2011 & SSSIM \\
\hline
\end{tabular}

Note. The first column is the experiment designation, the second indicates the period, and the third describes the data used to initialize these coupled model experiments. $\mathrm{T}_{\mathrm{Z}}$ and $\mathrm{S}_{\mathrm{Z}}$ stands for subsurface temperature and salinity, respectively; $\mathrm{SSS}_{\mathrm{OI}}$ is the optimal interpolation of near-surface in situ salinity.

${ }^{\mathrm{a}}$ The SSS OI_ASSIM experiment is used to initialize SSS_ASSIM starting in September 2011.

a)

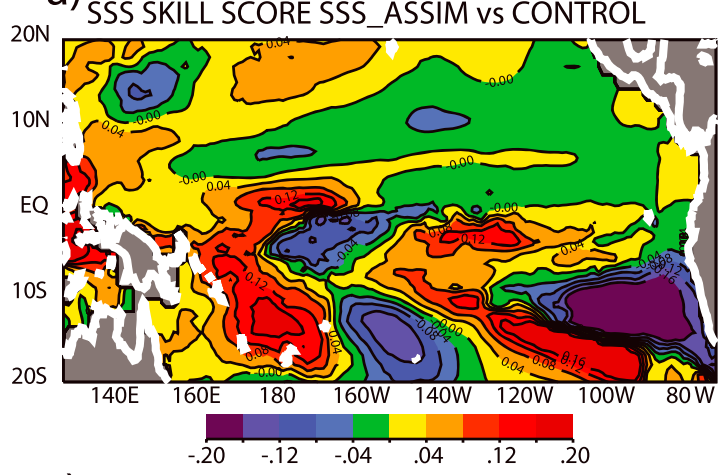

C)
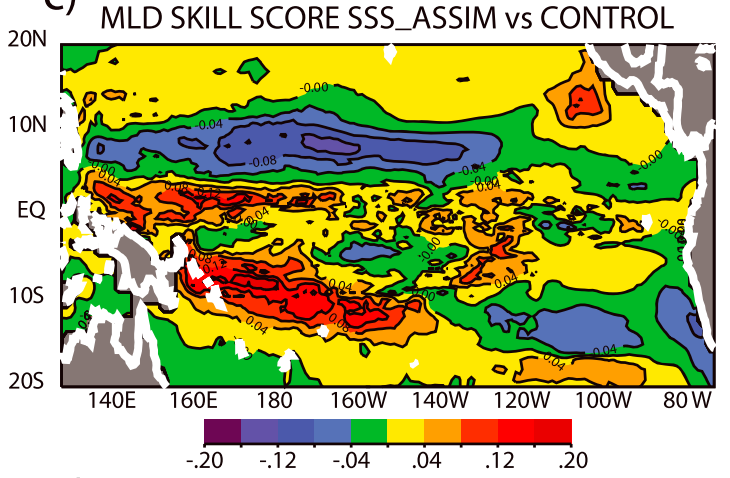

e) SL SKILL SCORE SSS_ASSIM vs CONTROL

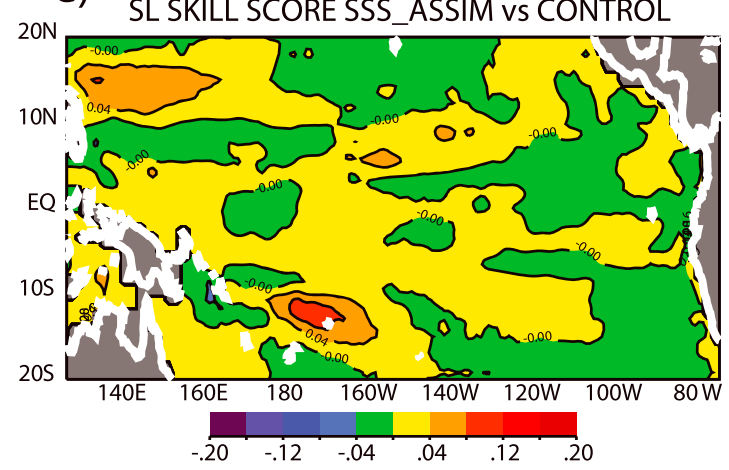

b)

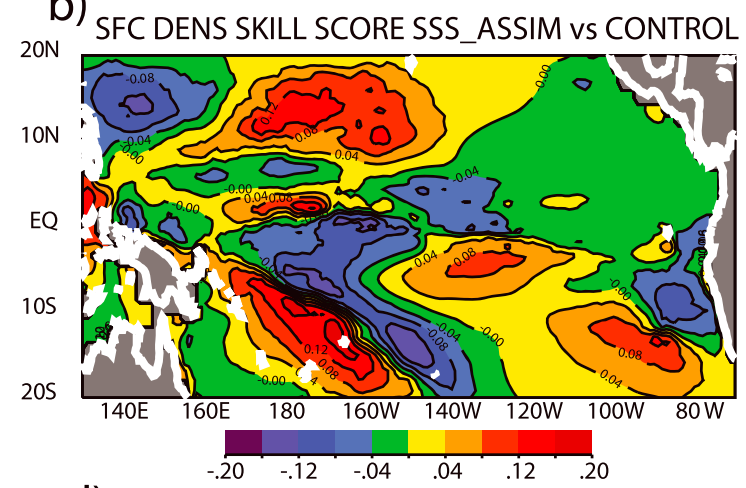

d)

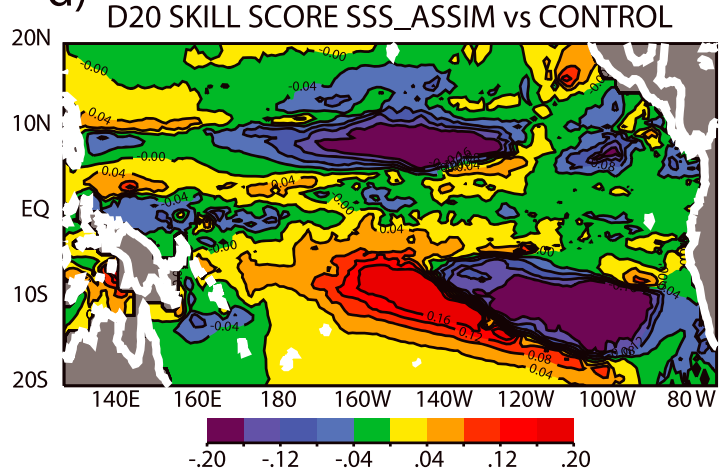

Figure 1. Results of skill score (skill score $=1-\left(\mathrm{RMSD}_{\mathrm{SSS}} \mathrm{ASSIM}_{\mathrm{ASMSD}} / \mathrm{RMNTROL}_{\mathrm{C}}\right)$ where the RMSD is formulated between the model and observed values. Unitless values are positive where the experiment that assimilates satellite SSS (SSS_ASSIM) outperforms the CONTROL that withholds satellite SSS. Variables are (a) SSS, (b) density of the mixed layer, (c) MLD, (d) depth of the $20{ }^{\circ} \mathrm{C}$ isotherm, and (e) sea level for September 2011 to September 2017. SSS $=$ sea surface salinity; MLD = mixed layer depth; SL = sea level. 
a)

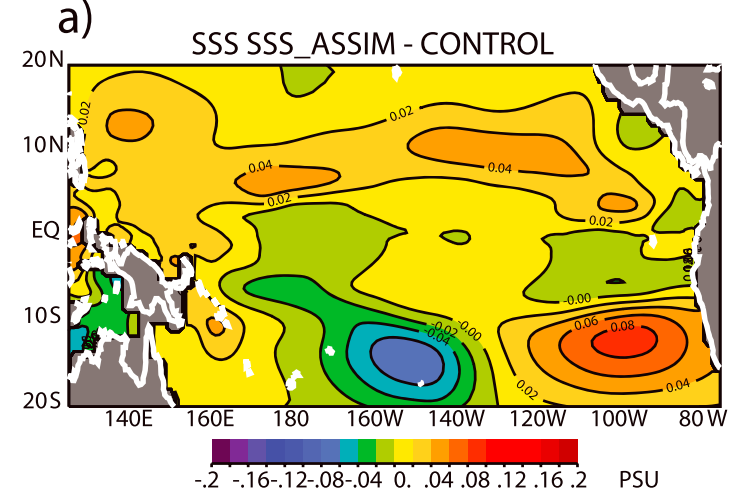

c)

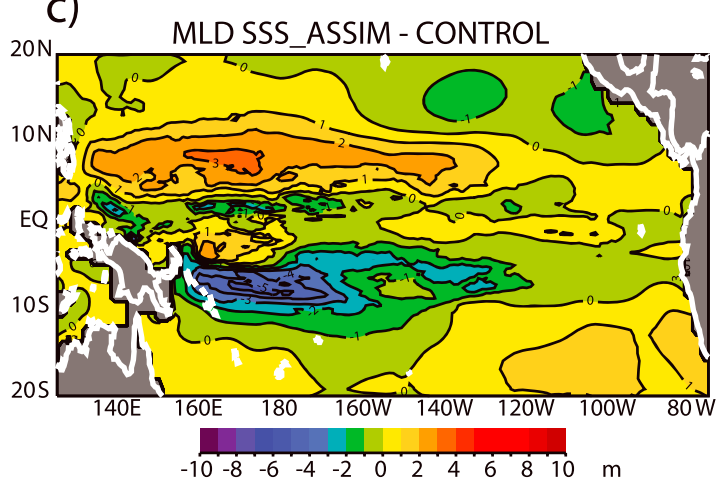

e) b)

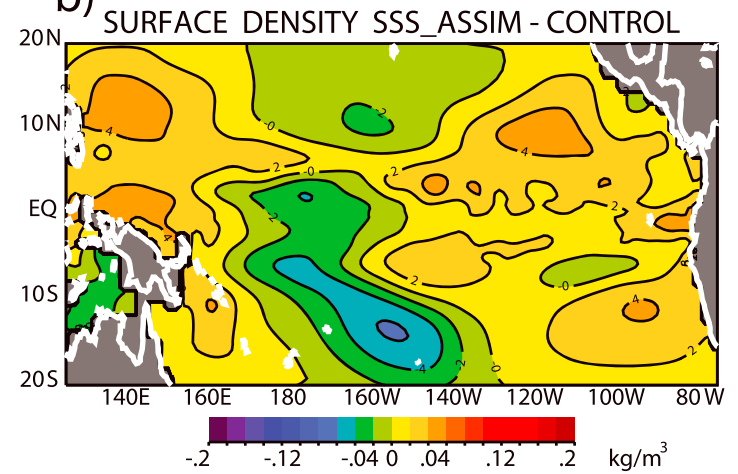

d)

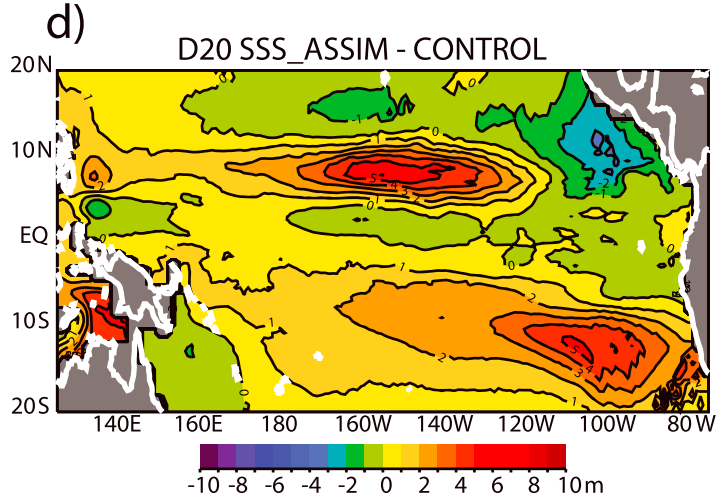

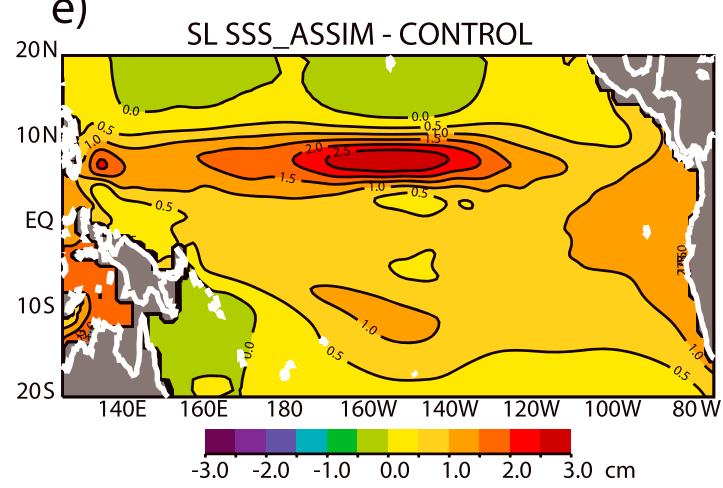

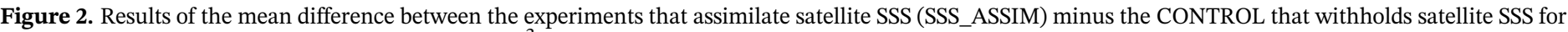
(a) SSS (psu) and (b) density of the mixed layer $\left(\mathrm{kg} / \mathrm{m}^{3}\right.$ ) (c) MLD (m), (d) depth of the $20{ }^{\circ} \mathrm{C}$ isotherm (m), and (e) sea level (cm) for September 2011 to September 2017. SSS = sea surface salinity; MLD = mixed layer depth; SL = sea level.

MLD than the CONTROL experiment does. A similar improvement in the SSS_ASSIM experiment versus CONTROL can also be seen in the depth of the $20{ }^{\circ} \mathrm{C}$ isotherm (Figure 1d) and sea level (Figure 1e). The improvement in these variables is important but as we will shortly demonstrate, the positive impact of SSS assimilation on MLD will prove to be the key for improving ENSO forecasts.

The mean differences, SSS_ASSIM minus CONTROL, are presented to highlight the impacts of satellite SSS assimilation on the mean ocean reanalysis state. Figure 2a shows that assimilation of SSS increases surface salinity along the ITCZ between $5^{\circ} \mathrm{N}$ and $15^{\circ} \mathrm{N}$ and in the southeast Pacific. In addition, freshening occurs over most of the tropical Pacific between $10^{\circ} \mathrm{S}$ and $5{ }^{\circ} \mathrm{N}$, especially in the western Pacific warm/fresh pool, east of $120^{\circ} \mathrm{W}$, and just east of the SPCZ. Changes in SSS brought about by assimilation translate to density changes of the model layer nearest the surface. The patterns of near-surface density (Figure $2 b$ ) generally match SSS. Lower density can be seen between roughly $170^{\circ} \mathrm{E}$ and $150^{\circ} \mathrm{W}$ for all latitudes. The density at the equator is mostly lower than values poleward east of $170^{\circ} \mathrm{E}$. 


\section{NINO3.4 REGION ANOM}

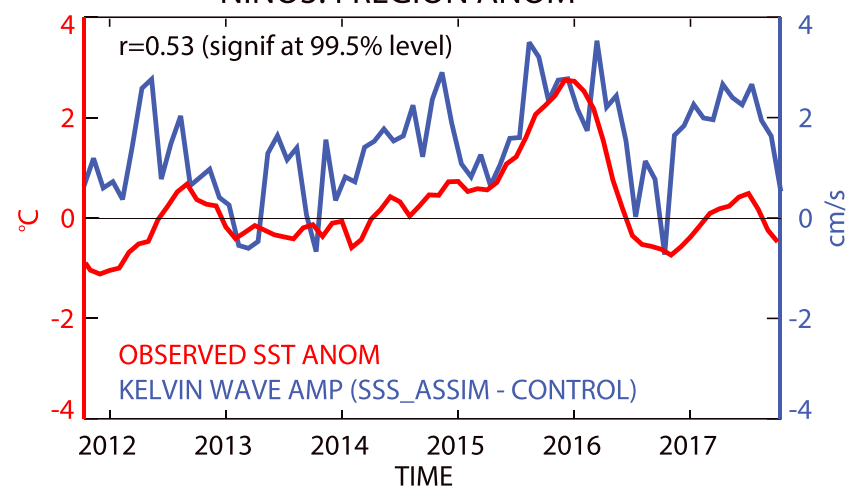

Figure 3. Red curve is the observed NINO3.4 SST anomaly from Reynolds et al. (2002) in ${ }^{\circ} \mathrm{C}$ (left axis). Blue curve is the Kelvin wave amplitude differences SSS_ASSIM minus CONTROL in cm/s (right axis). Significant correlation of 0.53 between the two shows that the Kelvin wave amplitude (and ENSO signal) is enhanced due to SSS assimilation. SSS = sea surface salinity; SST = sea surface temperature.
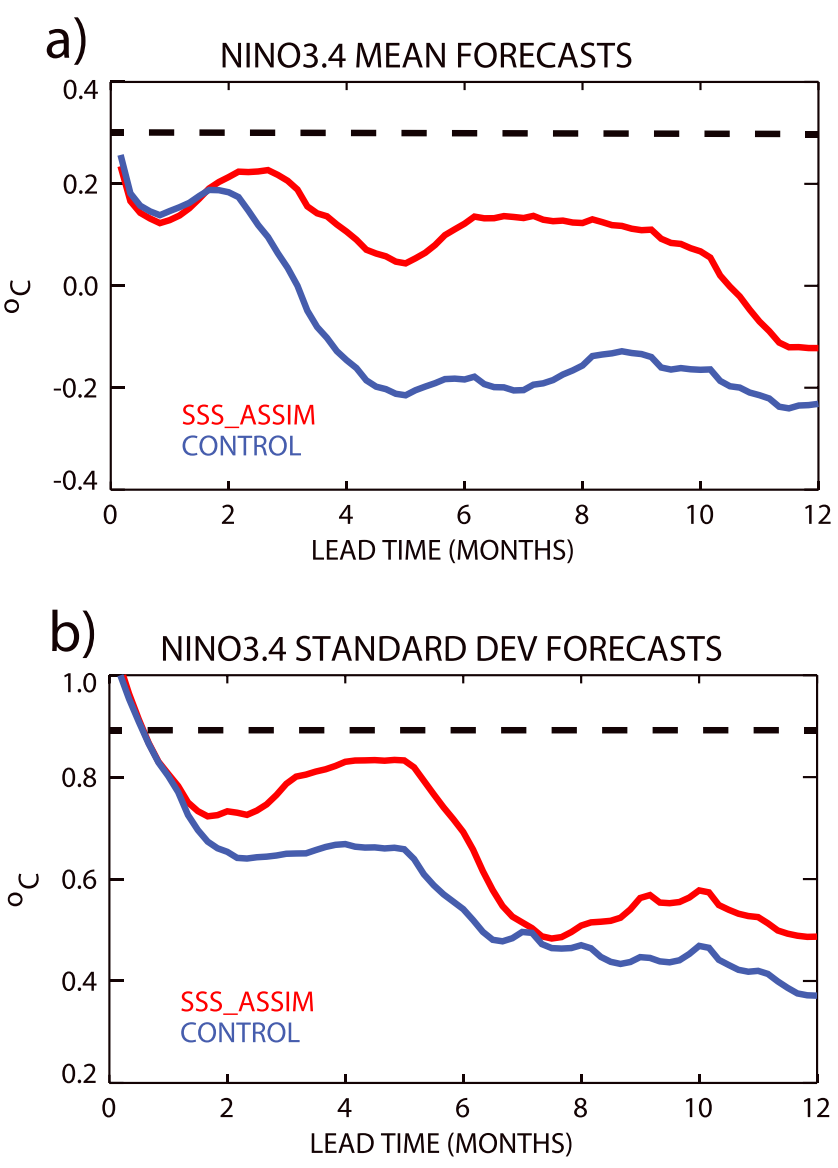

Figure 4. Statistics for (a) mean and (b) standard deviation for NINO3.4 SST anomalies are shown for the period September 2011 to September 2017. The red and blued curves correspond to SSS_ASSIM and CONTROL experiments, respectively. The mean $\left(0.33^{\circ} \mathrm{C}\right)$ and standard deviation $\left(0.89^{\circ} \mathrm{C}\right)$ for the observations are also included for reference (black dash lines). SSS = sea surface salinity.
Density changes near the surface directly impact the MLD. Figure 2c shows that overall shoaling of the MLD is evident between $10{ }^{\circ} \mathrm{S}$ and $\sim 5{ }^{\circ} \mathrm{N}$ and this feature is broadly consistent with the results of Chakraborty et al. (2015) that assimilated Aquarius SSS data. This MLD shoaling is coincident with thinning of the depth of the $20^{\circ} \mathrm{C}$ isotherm (a proxy for the depth of the thermocline) in Figure $2 \mathrm{~d}$ such that the equatorial waveguide is much shallower than both north and south of the equator west of $120^{\circ} \mathrm{W}$ and is consistent with the meridional gradient pattern of the density plot (Figure $2 \mathrm{~b}$ ). In a similar fashion, the mean SL also increases just off the equator at about $10^{\circ} \mathrm{S}$ and $8^{\circ} \mathrm{N}$ and in the far eastern equatorial Pacific due to assimilation of SSS (Figure 2e).

The period chosen for this study, September 2011 until September 2018, exhibited a wide variety of ENSO activity. The NINO3.4 index (Figure 3, red line) shows a weak La Niña from September 2011 to March 2012 and a major El Niño extending from November 2014 to March 2016, peaking in December of 2015. More recently, minor La Niña events in August to December 2016 and October to March 2017 also occurred. In 2018 (not shown), the NINO3.4 SST anomaly rose steadily out of La Niña to peak near $0.4^{\circ} \mathrm{C}$ in September 2018 .

ENSO is a complex air-sea coupled process that manifests as oceanic Kelvin and Rossby waves (Jin, 1997; Kessler et al., 1995). For example, Santoso et al. (2015) describes the Kelvin wave actions that went into the development and demise of the big 2015 El Nino. For our period, the patterns taken together in Figure 2 lead to an amplifying effect to enhance the Kelvin signal. To demonstrate this feature, the SL from both experiments have first been converted to geostrophic currents (Picaut \& Tournier, 1991) and then the Kelvin wave amplitude has been estimated using the technique of Delcroix et al. (1994). Finally, the CONTROL Kelvin signal has been subtracted from the SSS_ASSIM experiment (blue curve in Figure 3) and compared to the NINO3.4 SST anomaly index (red curve in Figure 3). The high correspondence between the Kelvin wave amplitude difference and the ENSO index indicates that SSS assimilation acts to enhance the Kelvin signal of ENSO. The correlation of the two time series is $r=0.53$ which is significant at the $99.5 \%$ level. Thus, a thinner MLD and shoaled thermocline within the equatorial waveguide allows wind stress air/sea coupling to be "more efficient" with enhanced ENSO response due to SSS assimilation. This amplification of the Kelvin wave due to decreased MLD is expected due to the fact that MLD is in the denominator of the equations defining the sea level response of the first and second mode Kelvin waves (see, e.g., Cravatte et al., 2003; equation (1)). Note that the first mode Rossby wave was also analyzed, but the correlation with the NINO3.4 SST anomaly was not significant $(\mathrm{r}=0.21)$ and was therefore not discussed.

The significant correlation between the Kelvin wave differences and the ENSO signal in Figure 3 establishes that assimilation of SSS leads to a more realistic, time-varying Kelvin wave amplitude in the initial state. Now, we demonstrate that assimilation of satellite SSS also leads to improved ENSO predictions. For each month, September 2011 to September 2017, 12-month-coupled forecasts are initialized from the CONTROL and SSS_ASSIM reanalyses. Figures 4 and 5 show the longterm validation statistics for SSS_ASSIM (red curve) and CONTROL (blue curve) versus the observed SST NINO3.4 anomaly (Reynolds et al., 2002, as shown in Figure 3 red curve). In addition, the Steiger's Z test (Steiger, 

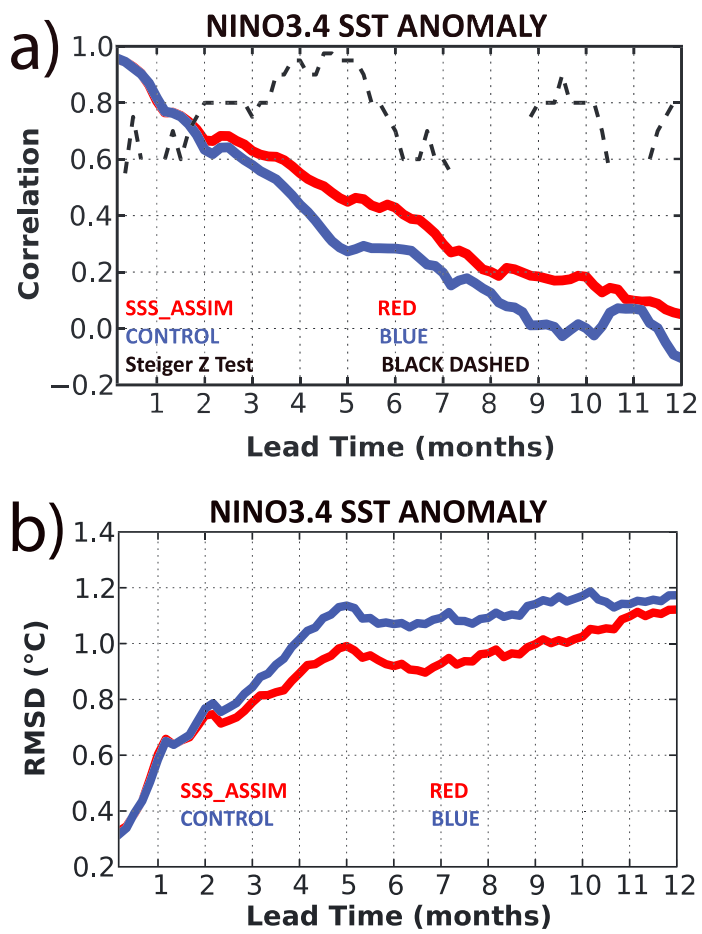

Figure 5. Validation of coupled model results for the period September 2011 to August 2018 using (a) correlation and (b) RMSD versus observed NINO3.4 SST anomaly. The solid blue curve is initialized using the CONTROL experiment; the red curve validates the assimilation of a combination of Aquarius and SMAP SSS (SSS_ASSIM). The thin dotted lines show the significance of the differences assuming SSS_ASSIM (red) is greater than CONTROL (blue) using the Steiger's Z Test. Note that results of the Steiger's $\mathrm{Z}$ test are not shown when the significance drops below 55\% and is undefined when the blue curve exceeds red curve. RMSD = root-meansquare difference; $\mathrm{SST}=$ sea surface temperature.
1980) estimates the significance of the differences between correlations as applied in, for example, Uehara et al. (2014); black dashed curve in Figure 5a).

Figure 4a shows that the mean NINO3.4 SST anomaly for the SSS_ASSIM experiment is larger for the SSS_ASSIM with respect to the CONTROL experiment. Thus, the increased downwelling signal of the Kelvin wave (positive values as seen in Figure 3 blue curve) leads to an overall warming in the NINO3.4 region for the SSS_ASSIM case. Between 2- and 10-month forecast lead times, the SST anomaly is warmer by more than $0.2^{\circ} \mathrm{C}$ and these warmer forecasts initialized from the SSS_ASSIM reanalysis are more accurate with respect to observations (i.e., the black dash line of $0.33{ }^{\circ} \mathrm{C}$ observed during this period). In addition, the variability of the SSS_ASSIM forecasts is more accurate with respect to the observed value of $0.89{ }^{\circ} \mathrm{C}$ for this period. So, a more realistic Kelvin wave amplitude, brought about by shallower MLD and by more accurate near-surface density from satellite SSS assimilation, leads to improved mean and variability of ENSO forecasts.

For the correlation plot, the experiment that assimilates satellite SSS (red curve in Figure 5a) shows high correlation and improved correspondence with observations over almost the entire 12-month forecast period. In particular, this improvement brought about by SSS assimilation is especially evident from 2- to 7- month and 9- to 10.5-month lead times with the significance generally exceeding $60 \%$, peaking at $98 \%$ at 4.5 months and correlation differences are as high as 0.18 for 5- and 9.5-month lead times. Another way to look at these results is that individual correlations for 72 months exceed the $99.5 \%$ significance when the correlation, $r>0.36$ (assuming seasonal decorrelation scales). Using this metric, useful ENSO forecasts are extended from 4.5 months to nearly 7 months with satellite SSS assimilation.

The RMSD of the forecast minus observed NINO3.4 SST anomaly reinforces the improvement brought about by satellite SSS assimilation (Figure 5b). Over the entire forecast period, the experiment that assimilates satellite SSS (red curve) outperforms the experiment excluding SSS (blue curve). SSS_ASSIM RMSD is lower by more than $0.17^{\circ} \mathrm{C}$ at 6 - to 7-month lead time. Thus, the significant improvement of the SSS_ASSIM coupled forecasts observational biases demonstrates the positive impact of satellite SSS assimilation.

\section{Summary and Conclusions}

Two experiments are compared: one with assimilation of satellite SSS assimilation and the other withholding satellite SSS. Differences between these experiments show that SSS and density are reduced near the equator and MLD is shallower over much of the tropical Pacific. In addition, the thermocline is shoaled near the equatorial waveguide. The combined impacts of SSS assimilation are to amplify the oceanic Kelvin wave signal in the tropical Pacific. Coupled experiments, initialized from SSS assimilation, significantly outperform those withholding SSS assimilation. By improving near-surface density structure via satellite SSS assimilation, ENSO forecasts are improved with respect to observed NINO3.4 SST anomalies for both the temporal (i.e., correlation) and amplitude (RMSD) signal particularly from 2- to 10-month lead times.

In this study, we use the MERRA-2 atmospheric reanalyses to force our ocean model assimilation experiments. Even though MERRA-2 assimilates all available atmospheric observations, ocean reanalyses forced by these state-of-the-art evaporation and precipitation fields are still lacking accurate SSS, near-surface density, and MLD fields, as evident by the relatively poor results of the CONTROL coupled forecasts. On the other hand, the results from this paper demonstrate that SSS assimilation improves the near-surface ocean state leading to improved coupled ENSO forecasts, thus reaffirming and extending our previous 
results (e.g., Hackert et al., 2014). Although there are currently very limited data available, the encouraging results of this study and of operational ocean-only data assimilation experiments (e.g., Martin et al., 2018; Tranchant et al., 2018) lead us to expect that assimilation of satellite SSS into more realistic operational forecast systems will result in improved ENSO forecasts. Therefore, we reassert the major conclusions of Tranchant et al. (2018) and Martin (2016), namely, that SSS assimilation should be routinely included as an essential observed quantity for operational coupled modeling since SSS assimilation can offset shortcomings in atmospheric forcing fields of evaporation and precipitation. Finally, we advocate for ensured continuity of space-based salinity measurements.

\section{Acknowledgments}

We would like to thank the many universities, private companies, and Government agencies that developed and compiled the Argo, GTSPP, TAO/RAMA moorings, WOA013, AVISO, and MERRA-2 data products. In addition, we would like to recognize the Aquarius and SMAP teams who developed hardware and algorithms, processed the data, and continue to improve the various products. We would also like to acknowledge the contribution of the reviewers whose suggestions improved this paper significantly. This research is supported by the Ocean Salinity Science Team (NNH16ZDA001-OSST). The MERRA2 data used to force the ocean model initialization is located at https://gmao. gsfc.nasa.gov/reanalysis/MERRA-2/ data_access/, the observation data repositories are sited within the text, and individual forecasts and forecast initializations (i.e., reanalyses) for CONTROL and SSS_ASSIM are available at https://gmao.gsfc.nasa.gov/ gmaoftp/ehackert/ICCM_results/ website. In addition, the basis functions and model forecast error covariance that comprise the EROKF are available at this same location.

\section{References}

AVISO (2013), "The altimeter products were produced by Ssalto/Duacs and distributed by Aviso, with support from Cnes (http://www. aviso.oceanobs.com/duacs/).” in SSALTO/DUACS User Handbook:(M)SLA and (M)ADT Near-Real Time and Delayed Time Products, edited by AVISO, p. 58, http://www.aviso.oceanobs.com/en/data/products/sea-surface-height-products/global/msla/index.html.

Ballabrera-Poy, J., Busalacchi, A. J., \& Murtugudde, R. (2001). Application of a reduced-order Kalman filter to initialize a coupled atmosphere-ocean model: Impact on the prediction of El Niño. Journal of Climate, 14(8), 1720-1737. https://doi.org/10.1175/15200442(2001)014<1720:AOAROK >2.0.CO;2

Ballabrera-Poy, J., Murtugudde, R., \& Busalacchi, A. J. (2002). On the potential impact of sea surface salinity observations on ENSO predictions. Journal of Geophysical Research, 107(C12), 8007. https://doi.org/10.1029/2001JC000834

Balmaseda, M., \& Anderson, D. (2009). Impact of initialization strategies and observations on seasonal forecast skill. Geophysical Research Letters, 36, L01701. https://doi.org/10.1029/2008GL035561

Boyer, T. P., Antonov, J. I., Baranova, O. K., Coleman, C., Garcia, H. E., Grodsky, A., et al. (2013). World Ocean Database 2013, paper presented at NOAA Atlas NESDIS, (Vol. 72). Washington, D.C: U.S. Government Printing Office.

Busalacchi, A. J., McPhaden, M. J., \& Picaut, J. (1994). Variability in equatorial pacific sea-surface topography during the verification phase of the Topex/Poseidon Mission. Journal of Geophysical Research, 99(C12), 24,725-24,738. https://doi.org/10.1029/94JC01638

Cane, M. A., Kaplan, A., Miller, R. N., Tang, B. Y., Hackert, E. C., \& Busalacchi, A. J. (1996). Mapping tropical Pacific sea level: Data assimilation via a reduced state space Kalman filter. Journal of Geophysical Research, 101(C10), 22,599-22,617. https://doi.org/10.1029/ 96JC01684

Chakraborty, A., Sharma, R., Kumar, R., \& Basu, S. (2015). Joint assimilation of Aquarius-derived sea surface salinity and AVHRR-derived sea surface temperature in an ocean general circulation model using SEEK filter: Implication for mixed layer depth and barrier layer thickness. Journal of Geophysical Research: Oceans, 120, 6927-6942. https://doi.org/10.1002/2015JC010934

Cravatte, S., Picaut, J., \& Eldin, G. (2003). Second and first baroclinic Kelvin modes in the equatorial Pacific at intraseasonal timescales. Journal of Geophysical Research, 108(C8), 3266. https://doi.org/10.1029/2002JC001511

Dai, A. G., \& Trenberth, K. E. (2002). Estimates of freshwater discharge from continents: Latitudinal and seasonal variations. Journal of Hydrometeorology, 3(6), 660-687. https://doi.org/10.1175/1525-7541(2002)003<0660:EOFDFC >2.0.CO;2

Delcroix, T., Boulanger, J. P., Masia, F., \& Menkes, C. (1994). Geosat-derived sea-level and surface current anomalies in the equatorial pacific during the 1986-1989 El-Niño and La-Niña. Journal of Geophysical Research, 99(C12), 25,093-25,107. https://doi.org/10.1029/94JC02138

Fore, A., S. Yueh, W. Tang, and A. Hayashi (2016), SMAP salinity and wind speed data user's guide, Version 2 Rep., 24 pp, Jet Propulsion Laboratory, California Institute of Technology, Pasadena, Ca.

Gelaro, R., McCarty, W., Suárez, M. J., Todling, R., Molod, A., Takacs, L., et al. (2017). The modern-era retrospective analysis for research and applications, Version 2 (MERRA-2). Journal of Climate, 30(14), 5419-5454. https://doi.org/10.1175/jcli-d-16-0758.1

Gent, P. R., \& Cane, M. A. (1989). A reduced gravity, primitive equation model of the upper equatorial ocean. Journal of Computational Physics, 81(2), 444-480. https://doi.org/10.1016/0021-9991(89)90216-7

Hackert, E. (2016). The role of the Indian Ocean sector and sea surface salinity for prediction of the coupled Indo-Pacific system-PhD Dissertation, 180 pp. College Park, MD 20742: University of Maryland. https://drum.lib.umd.edu/handle/1903/18758

Hackert, E., Ballabrera-Poy, J., Busalacchi, A., Zhang, R. H., \& Murtugudde, R. (2011). Impact of sea surface salinity assimilation on coupled forecasts in the tropical Pacific. Journal of Geophysical Research, 116, C05009. https://doi.org/10.1029/2010JC006708

Hackert, E., Busalacchi, A., \& Ballabrera-Poy, J. (2014). Impact of Aquarius sea surface salinity observations on coupled forecasts for the tropical Indo-Pacific Ocean. Journal of Geophysical Research: Oceans, 119, 4045-4067. https://doi.org/10.1002/2013JC009697

Hackert, E. C., Busalacchi, A. J., Carton, J., Murtugudde, R., Arkin, P., \& Evans, M. N. (2017). The role of the Indian Ocean sector for prediction of the coupled Indo-Pacific system: Impact of atmospheric coupling. Journal of Geophysical Research: Oceans, 122, 2813-2829. https://doi.org/10.1002/2016JC012632

Huang, R. X. (1993). Real fresh-water flux as a natural boundary-condition for the salinity balance and thermohaline circulation forced by evaporation and precipitation. Journal of Physical Oceanography, 23(11), 2428-2446. https://doi.org/10.1175/1520-0485(1993)023<2428: RFFAAN $>2.0 . \mathrm{CO} ; 2$

Ji, M., Reynolds, R. W., \& Behringer, D. W. (2000). Use of TOPEX/Poseidon sea level data for ocean analyses and ENSO prediction: Some early results. Journal of Climate, 13(1), 216-231. https://doi.org/10.1175/1520-0442(2000)013<0216:UOTPSL>2.0.CO;2

Jin, F. F. (1997). An equatorial ocean recharge paradigm for ENSO. Part I: Conceptual model. Journal of the Atmospheric Sciences, 54(7), 811-829. https://doi.org/10.1175/1520-0469(1997)054<0811:AEORPF>2.0.CO;2

Kao, H.-Y., Lagerloef, G. S. E., Lee, T., Melnichenko, O., Meissner, T., \& Hacker, P. (2018). Assessment of Aquarius sea surface salinity. Remote Sensing, 10(9), 1341. https://doi.org/10.3390/rs10091341

Kessler, W. S., McPhaden, M. J., \& Weickmann, K. M. (1995). Forcing of intraseasonal Kelvin waves in the equatorial Pacific. Journal of Geophysical Research, 100(C6), 10,613-10,631. https://doi.org/10.1029/95JC00382

Kim, D., Kug, J. S., Kang, I. S., Jin, F. F., \& Wittenberg, A. T. (2008). Tropical Pacific impacts of convective momentum transport in the SNU coupled GCM. Climate Dynamics, 31(2-3), 213-226. https://doi.org/10.1007/s00382-007-0348-4

Kucharski, F., Molteni, F., King, M. P., Farneti, R., Kang, I.-S., \& Feudale, L. (2013). On the need of intermediate complexity general circulation models a "SPEEDY" example. Bulletin of the American Meteorological Society, 94(1), 25-30. https://doi.org/10.1175/bams-d-1100238.1 
Kucharski, F., Molteni, F., \& Yoo, J. H. (2006). SST forcing of decadal Indian Monsoon rainfall variability. Geophysical Research Letters, 33 , L03709. https://doi.org/10.1029/2005GL025371

Lagerloef, G., Colomb, F. R., le Vine, D., Wentz, F., Yueh, S., Ruf, C., et al. (2008). The Aquarius/SAC-D Mission: Designed to meet the salinity remote-sensing challenge. Oceanography, 21(1), 68-81. https://doi.org/10.5670/oceanog.2008.68

Lilly, J. M., and G. Lagerloef (2008), Aquarius level 3 processing algorithm theoretical basis document. Version 0.9. (ftp://podaac-ftp.jpl. nasa.gov/allData/aquarius/docs/v2/AquariusLevel3_GriddingSmoothingPaper_Lilly\&Lagerloef2008.pdf)Rep., 14 pp, Jet Propulsion Lab, Pasadena, CA.

Locarnini, R. A., Mishonov, A. V., Antonov, J. I., Boyer, T. P., Garcia, H. E., Baranova, O. K., et al. (2013). In S. Levitus (Ed.), A. Mishonov Technical EdWorld Ocean Atlas 2013, Volume 1: Temperature, 43 pp, NOAA Atlas NESDIS, (Vol. 73). Silver Spring, MD: NOAA.

Martin, M. J. (2016). Suitability of satellite sea surface salinity data for use in assessing and correcting ocean forecasts. Remote Sensing of Environment, 180, 305-319. https://doi.org/10.1016/j.rse.2016.02.004

Martin, M. J., King, R. R., While, J., \& Aguiar, A. (2018). Assimilating satellite sea surface salinity data from SMOS, Aquarius and SMAP into a global ocean forecasting system. Quarterly Journal of the Royal Meteorological Society, 145(719), 705-726. https://doi.org/10.1002/ qj.3461

Meissner, T., Wentz, F. J., \& Le Vine, D. M. (2018). The salinity retrieval algorithms for the NASA Aquarius Version 5 and SMAP version 3 releases. Remote Sensing, 10(7), 1121. https://doi.org/10.3390/rs10071121

Molteni, F. (2003). Atmospheric simulations using a GCM with simplified physical parametrizations. I: Model climatology and variability in multi-decadal experiments. Climate Dynamics, 20(2), 175-191. https://doi.org/10.1007/s00382-002-0268-2

NODC (2006). NODC operational oceanographic data group: Global temperature salinity profile program, February 2006. Silver Spring, Maryland: U.S. Department of Commerce, National Oceanic and Atmospheric Administration, National Oceanographic Data Center. 20910Rep

Oke, P. R., Larnicol, G., Fujii, Y., Smith, G. C., Lea, D. J., Guinehut, S., et al. (2015). Assessing the impact of observations on ocean forecasts and reanalyses: Part 1, Global studies. Journal of Operational Oceanography, 8(sup1), S49-S62. https://doi.org/10.1080/ 1755876x.2015.1022067

Picaut, J., \& Tournier, R. (1991). Monitoring the 1979-1985 equatorial Pacific current transports with expendable bathythermograph data Journal of Geophysical Research, 96(S01), 3263-3277. https://doi.org/10.1029/90JC02066

Reynolds, R. W., Rayner, N. A., Smith, T. M., Stokes, D. C., \& Wang, W. Q. (2002). An improved in situ and satellite SST analysis for climate. Journal of Climate, 15(13), 1609-1625. https://doi.org/10.1175/1520-0442(2002)015<1609:AIISAS>2.0.CO;2

Roemmich, D., \& Gilson, J. (2009). The 2004-2008 mean and annual cycle of temperature, salinity, and steric height in the global ocean from the Argo Program. Progress in Oceanography, 82(2), 81-100. https://doi.org/10.1016/j.pocean.2009.03.004

Santoso, A., Cai, W., Collins, M., McPhaden, M., \& Jin, F.-F. (2015). ENSO extremes and diversity dynamics, teleconnections, and impacts. Bulletin of the American Meteorological Society, 96(11), 1969-1972.

Sprintall, J., \& Tomczak, M. (1992). Evidence of the barrier layer in the surface-layer of the tropics. Journal of Geophysical Research, 97(C5), 7305-7316. https://doi.org/10.1029/92JC00407

Steiger, J. H. (1980). Tests for comparing elements of a correlation matrix. Psychological Bulletin, 87(2), 245-251. https://doi.org/10.1037// 0033-2909.87.2.245

Tranchant, B., Remy, E., Greiner, E., \& Legalloudec, O. (2018). Data assimilation of SMOS observations into the Mercator Ocean operational system: Focus on the Nino 2015 event. Ocean Science Discussions, 2018, 1-29. https://doi.org/10.5194/os-2018-113

Uehara, H., Kruts, A. A., Mitsudera, H., Nakamura, T., Volkov, Y. N., \& Wakatsuchi, M. (2014). Remotely propagating salinity anomaly varies the source of North Pacific ventilation. Progress in Oceanography, 126, 80-97. https://doi.org/10.1016/j.pocean.2014.04.016

Yang, S. C., Rienecker, M., \& Keppenne, C. (2010). The impact of ocean data assimilation on seasonal-to-interannual forecasts: A case study of the 2006 El Nino event. Journal of Climate, 23(15), 4080-4095. https://doi.org/10.1175/2010jcli3319.1

Zhou, X. B., Tang, Y. M., \& Deng, Z. W. (2009). Assimilation of historical SST data for long-term ENSO retrospective forecasts. Ocean Modelling, 30(2-3), 143-154. https://doi.org/10.1016/j.ocemod.2009.06.015

Zhu, J., Huang, B., Zhang, R.-H., Hu, Z.-Z., Kumar, A., Balmaseda, M. A., et al. (2014). Salinity anomaly as a trigger for ENSO events. Scientific Reports, 4(1). https://doi.org/10.1038/srep06821

Zweng, M. M., Reagan, J. R., Antonov, J. I., Locarnini, R. A., Mishonov, A. V., Boyer, T. P., et al. (2013). In S. Levitus (Ed.), A. Mishonov Technical Ed.World Ocean Atlas 2013, Volume 2: Salinity, 39 pp, NOAA Atlas NESDIS, (Vol. 75). Silver Spring, MD: NOAA.

\section{Erratum}

In the originally published version of this article, a comment intended for the typesetters was included in error in the caption of Figure 5. The error has been corrected, and this may be considered the official version of record. 